\title{
Dealing with the fear of coronavirus and its negative psychological effects
}

\section{Editorial}

For months, the whole world and psychologists have started to focus on informative sessions and project-based studies to deal with the mass panic and anxiety caused by the corona virus. As the coronavirus outbreak spreads to more countries and the number of deaths increases, there is uncertainty about what will happen next.

Among these uncertainties, the most common (seemingly) behaviour that everyone automatically resorts to; It may be to purchase concrete consumption necessities such as toilet paper, pasta, pulses etc.

However, the secret subject of this situation is 'Panic Buying' as I call it. This can only be understood as a coping mechanism, because psychological fluctuation effects are already being felt in both individuals and societies. I have been saying from the very beginning: 'The unconscious responses of people to the spread of coronavirus will do us more harm than the disease itself'. In their social media accounts, people write "I am not afraid of COVID-19" or they are making humour on the virus. Actually, this is not a criticism, but my concern is the loss of the mind wave that causes panic spiral by exceeding the required amount of everything. The truth is, 'When the virus comes it won't do much damage or just fight for yourself.' doctrines can bring psychological problems on his back. Because the panic image is not only limited to a personal fantasy world buy also it shifts between disasters in general and today's media. In times of stress and panic, we tend to use strategies that are often used to survive.

When our tension-reduction strategies instead increase our anxiety, the 4 simple points of view I wrote below may help.

\section{Step back and see the whole picture}

Having a limited knowledge of the events that occur around can reveal a psychologically strong negative fight/flight reaction. For example, if COVID-19 has a lasting effect on the economy, you can start thinking first, then you can ask whether businesses are affected? What can cause if I lose my job? What happens if I lose my house then? You can create a vicious circle with these questions. Because of all these kind of questions are typically negative and can often lead to hysteria. It is important to control these "if it happens" statements. Avoid "what if" statements, take a step back to look at the bigger picture and focus on what you can do proactively in the present time.

\section{Determine what you can control}

It is very important how and from where we learned information about the epidemic over which we have no control. When things happen out of our control, we often try to create an emotional or objective fear to feel as though we still have a sense of control, and this makes us even more panicked. In such situations, true information from reliable sources will give you the feeling of strength and help you to be more calm.

For example, the World Health Organization constantly updates
Volume II Issue 4 - 2020

Sare Ucar
Clinical Psychologist, SWPS University, Poland

Correspondence: Sare Ucar, Clinical Psychologist, SWPS University, Poland, Email ucarsare88@gmail.com

Received: September II, 2020 | Published: September 2I, 2020

accurate information on coronavirus. Apart from this, channels such as the Mental Health Innovation Network will help you keep control by providing you the real and accurate information.

\section{Have a flexible life plan}

Another way to keep yourself alive during these tough times is to try to do as much as you can about familiar things in your life. Aim to continue your regular routines and activities as much as possible. Try to avoid to say; "What can I do inside my house, I am bored, my daily routine is killing me every day. I miss nature, sea, socialization." etc. Making your sentences will not help you and those around you and will not change the rules you need to follow right now. Try to adopt a flexible approach that allows you to make your plans every day as needed. Instead of looking at the world in a fearful way, be careful to look through a more flexible window.

\section{Find simple things to make you happy}

In times of crisis, we neglect our personal care because of intense anxiety. The truth is, in times of uncertainty, your concerns; You have to balance your physiological health with good nutrition, regular sleep and simple exercise movements you can do at home. If you're looking to have a productive afternoon, choose a comedy movie to lift your mood with humour that releases the positive neurotransmitter dopamine. Stay connected with others and overcome social distancing by reaching out to friends and family members through video calling. If you need professional support, try connecting with a mental health professional using a digital health platform. ${ }^{1-3}$

Do not forget that the written above are general recommendations. Every person is unique and special, so every technique may not be enough for everyone. If your situation has become unbearable, I recommend you to get professional support. 


\section{Funding}

None.

\section{Acknowledgments}

None.

\section{Conflicts of interest}

The author declares that there is no conflict of interest to declare.

\section{References}

1. Guan WJ, Ni ZY, Hu Y, et al. Clinical Characteristics of Coronavirus Disease 2019 in China. N Engl J Med. 2020;382:1708-1720.

2. NHS. Specialty guides: Coronavirus. 2020.

3. Wang D, Zhou M, Nie X, et al. Epidemiological characteristics and transmission model of Corona Virus Disease 2019 in China. $J$ Infect. 2020;80(5):e25-e27. 